\title{
Effect of switching administration of alendronate after teriparatide for the prevention of BMD loss around the implant after total hip arthroplasty, 2-year follow- up: a randomized controlled trial
}

\author{
Akira Morita', Naomi Kobayashi ${ }^{2 *}$, Hyonmin Choe ${ }^{1}$, Hiroyuki Ike', Taro Tezuka', Shota Higashihira ${ }^{1}$ and Yutaka Inaba ${ }^{1}$
}

\begin{abstract}
Background: Stress shielding after total hip arthroplasty (THA) can induce bone mineral density (BMD) loss around the femoral implant. Several studies using drug have described methods to prevent BMD loss around implants following THA. Switching from teriparatide to alendronate was reported to increase lumbar BMD; on the other hands, it is unclear whether switching from teriparatide to alendronate is effective around the implant. The aim of this study is that changes in BMD is compared in patients switched from teriparatide to alendronate, in patients treated with alendronate alone, and in control patients without medication after total hip arthroplasty.

Patients and methods: Patients were randomized into three groups, those switched to alendronate after teriparatide (switch: $n=17$ ), those receiving continuous alendronate (ALD: $n=15$ ), and control untreated patients (control: $n=16$ ) and followed up for 2 years after THA. Baseline periprosthetic BMD was measured by dual-energy X-ray absorptiometry (DEXA) 1 week after THA, followed by subsequent measurements at 1 and 2 years postoperatively. Lumbar BMD was also evaluated at preoperatively, 1 and 2 years postoperatively.
\end{abstract}

Results: Two years after surgery, BMD (\%) at zone 1 was significantly higher in the switch group than in the control group $(P=0.02)$. BMD (\%) at zone 7 was significantly higher in the switch and ALD groups than in the control group ( $P=0.01, P=0.03)$. Lumbar BMD (\%) anterior-posterior (AP) side was significantly higher in the switch group than in the ALD and control groups 2 years after surgery. On the other hand, lumbar BMD (\%) lateral side was significantly higher in the switch and ALD groups than control group 2 years after surgery.

Conclusions: Switching therapy had a significant effect on BMD of the lumbar spine and zones 1 and 7 at 2 years postoperatively. At zone 1 in particular, it was found to be more effective than ALD alone.

Trial registration: UMIN, registry number UMIN000016158. Registered 8 January 2015

Keywords: Bone mineral density (BMD), Total hip arthroplasty (THA), Teriparatide, Alendronate (ALD)

\footnotetext{
*Correspondence: naomik58@aol.com

${ }^{2}$ Department of Orthopaedic Surgery, Yokohama City University Medical

Center, 4-57 Urafune-cho, Minami-ku, Yokohama 232-0024, Japan

Full list of author information is available at the end of the article
}

(c) The Author(s). 2020 Open Access This article is distributed under the terms of the Creative Commons Attribution 4.0 International License (http://creativecommons.org/licenses/by/4.0/), which permits unrestricted use, distribution, and reproduction in any medium, provided you give appropriate credit to the original author(s) and the source, provide a link to the Creative Commons license, and indicate if changes were made. The Creative Commons Public Domain Dedication waiver (http://creativecommons.org/publicdomain/zero/1.0/) applies to the data made available in this article, unless otherwise stated. 


\section{Introduction}

Total hip arthroplasty (THA) is a promising surgical treatment, providing pain relief, functional recovery, and long-term stable clinical results, with 20-year implant survival rates higher than $90 \%[1,2]$. However, stress shielding can induce bone mineral density (BMD) loss around the femoral implant [3-5]. Although BMD loss around the implant has not been found to result in poorer clinical outcomes after THA, a large retrospective cohort study suggested that the use of bisphosphonate decreased the risk of revision after THA [6]. In addition, BMD loss around the implant may be associated with an increased risk of periprosthetic fractures [7]. Indeed, many periprosthetic fractures have been associated with decreased periprosthetic BMD [8]. Thus, prevention of BMD loss after THA seems to be clinically desirable.

Several recent studies have described methods to prevent BMD loss around implants following THA [9-11]. Teriparatide and alendronate, which have adverse effects on bone metabolism, are principal drugs for treating osteoporosis. A randomized controlled trial comparing teriparatide with alendronate for the prevention of BMD loss around the implant over 1 year [12] found that both significantly prevented BMD loss, particularly in the medial proximal femur. Although combination therapy with teriparatide and alendronate was not effective for osteoporosis [13], switching from teriparatide to alendronate was reported to increase lumbar BMD [14, 15]. These findings suggested that switching from teriparatide to alendronate may also have a positive effect on the BMD around the implant after THA.

The primary goal of this study was therefore to compare changes in BMD in three randomly assigned groups, patients switched from teriparatide to alendronate, patients treated with alendronate alone, and a control untreated group, for 2 years after THA.

\section{Patients and methods}

This randomized controlled trial (RCT) was an extension of a previous reported study registered in the University Hospital Medical Information Network (UMIN) clinical trial registry (registry number: UMIN000016158) 9 . Forty-eight subjects, 42 women, and 6 men, were included, all of whom provided written informed consent and underwent primary cementless THA in our hospital from December 2011 to September 2013. Their mean ( \pm standard deviation) age at the time of surgery was $65 \pm$ 10 years, and their mean body mass index (BMI) was $23.4 \pm 3.9 \mathrm{~kg} / \mathrm{m}^{2}$. All patients were implanted with the same cementless femoral component (SL-PLUS MIA, Smith and Nephew, Inc. Memphis, TN), cementless acetabular component (REFLECTION, Smith and Nephew, Inc.), and cross-linked polyethylene liner (XLPE liner, Smith and Nephew, Inc.). Patients were excluded if they had (1) a history of disorder that might affect the bone or mineral metabolism, (2) gastrointestinal disease, (3) renal dysfunction, or (4) previously taken estrogen, progesterone, androgens, calcitonin, glucocorticoid, bisphosphonate, calcium supplements, or vitamin D. Figure 1 shows the study flow diagram. Of the 48 patients, 17 were randomized to the switch group, 15 to the ALD group, and 16 to the control group (Fig. 1). Patients in the switch group were started on daily injections of $20 \mu \mathrm{g} /$ day teriparatide (Forteo, Eli Lilly Japan K.K.), beginning 2 weeks after THA and continuing for 1 year. These patients were subsequently switched to oral administration of ALD (35 mg/week) continuously for 1 year. Patients in the ALD group were started on oral administration of alendronate (35 mg/week; Bonalon, Teijin Pharma Limited) beginning 2 weeks after THA and continuing for 2 years. Patients in the control group received no drug for 2 years. During the observation period, 7 patients discontinued the trial, four (two in the switch and two in the ALD groups) due to discontinued drug use, two (one in the switch and one in the ALD groups) for discontinued follow-up, and one in the control group due to THA in the contralateral hip 24 weeks after the primary THA. Patient activity levels and clinical outcomes were evaluated by measuring the University of California, Los Angeles (UCLA), activity score, Japanese Orthopaedic Association (JOA) hip score, and Harris Hip Score (HHS) preoperatively and after 1 and 2 years. All patients started to use a wheelchair on the first postoperative day, commencing gait exercises with fullweight bearing as soon as possible.

Baseline periprosthetic BMD was measured 1 week after THA, followed by subsequent measurements at 1 and 2 years using dual-energy X-ray absorptiometry (DEXA) (QDR 2000, Hologic, Waltham, MA). The periprosthetic zones described by Gruen were used for the regions of interest (ROIs) (Fig. 2). Baseline lumbar BMD was also measured preoperatively, followed by subsequent measurements at 1 and 2 years postoperatively for the L2 to L4 lumbar anterior-posterior (AP) direction and lateral direction using DEXA. The rate of change (\%) of BMD relative to baseline was statistically evaluated using one-way analysis of variance and TukeyKramer method. All statistical analyses were performed using EZR software [16], which modified version of $\mathrm{R}$ commander designed to add statistical functions frequently used in biostatistics. A $p$ value $<0.05$ was considered statistically significant.

\section{Results}

The baseline demographic characteristics and preoperative activity and functional score in each group are shown in Table 1. There were no significant differences in any factor among these groups. Table 2 shows activity and functional score 2 years after surgery in each group. 


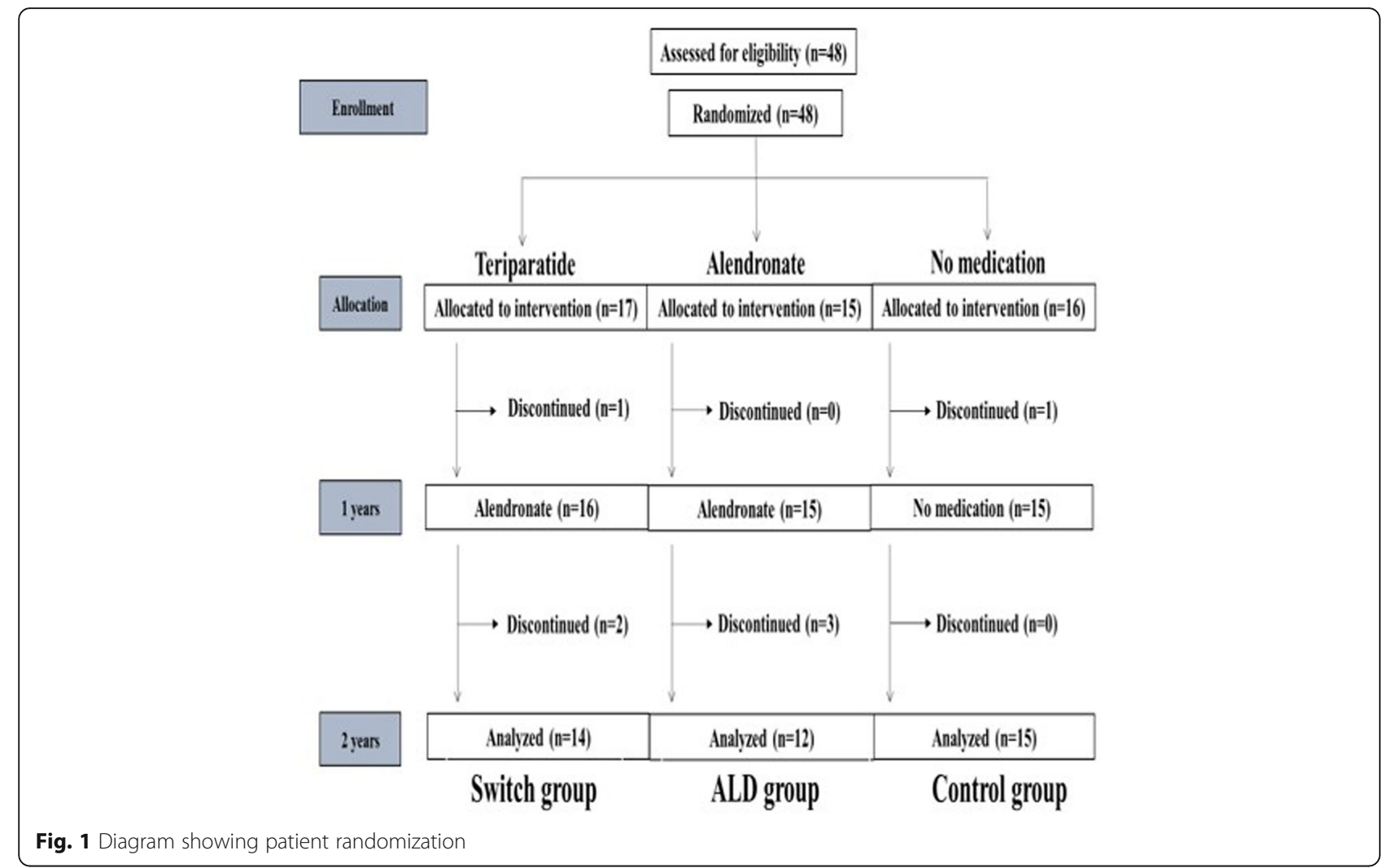

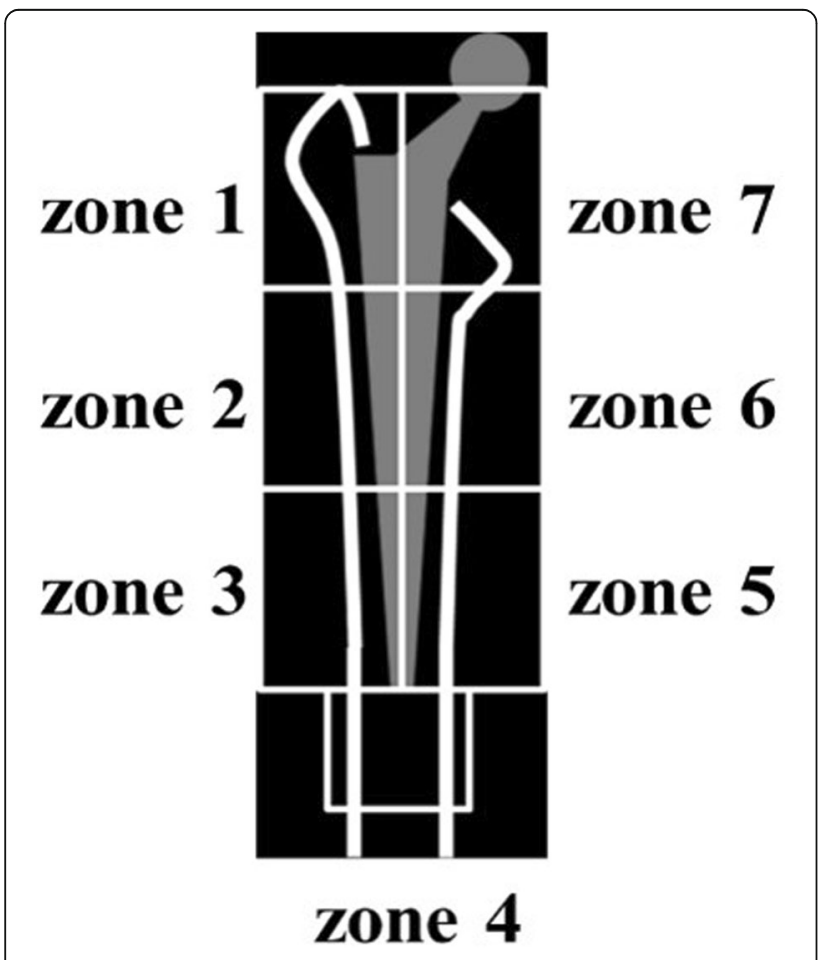

Fig. 2 Gruen's zone classification
There were no significant differences in any of these scores. Figure 3 shows the rate of BMD change (\%) of each zone in the control group up to 2 years after surgery. Relative to baseline, the rates of BMD change (\%) at 2 years after surgery were $-11.6 \pm 13.1 \%$ at zone 1 , $11.0 \pm 15.5 \%$ at zone $2,-2.7 \pm 6.3 \%$ at zone $3,-0.4 \pm$ $6.4 \%$ at zone $4,+0.8 \pm 8.3 \%$ at zone $5,-16.3 \pm 8.6 \%$ at zone 6 , and $-35.4 \pm 10.7 \%$ at zone 7 . The BMD changes (\%) from baseline to 2 years differed significantly at zone 1 and $7(P<0.01$ each). Figure 4 shows the rates of BMD changes in the switch group. Relative to baseline, the rates of BMD change (\%) at 2 years after surgery were $+4.7 \pm 13.6 \%$ at zone $1,-6.4 \pm 13.0 \%$ at zone 2 , $6.5 \pm 8.2 \%$ at zone $3,+3.4 \pm 4.5 \%$ at zone $4,+1.5 \pm$ $5.3 \%$ at zone $5,-1.0 \pm 22.7 \%$ at zone 6 , and $-15.7 \pm$ $15.6 \%$ at zone 7 . Figure 5 shows the rates of BMD changes in the ALD group. Relative to baseline, the rates of BMD change (\%) at 2 years after surgery were $+1.7 \pm$ $18.2 \%$ at zone $1,-2.5 \pm 14.2 \%$ at zone $2,-1.9 \pm 7.3 \%$ at zone $3,+3.1 \pm 4.2 \%$ at zone $4,-2.1 \pm 10.0 \%$ at zone 5 , $-4.9 \pm 16.7 \%$ at zone 6 , and $-18.2 \pm 22.5 \%$ at zone 7 . Figure 6 shows the differences in BMD changes at zone 1 in the three groups. There was a significant difference between the switch and control groups after 2 years postoperatively $(P=0.02)$, but no significant difference between the ADL and control groups. Figure 7 shows BMD changes in the three groups at zone 7 . There was 
Table 1 Baseline demographic and clinical characteristics of the three patient groups

\begin{tabular}{|c|c|c|c|c|}
\hline & Switch & ALD & Control & $P$ value \\
\hline Number of subjects & 17 & 15 & 16 & \\
\hline Male/female & $1 / 16$ & $1 / 14$ & $4 / 11$ & \\
\hline Average age, years & $65.8 \pm 10.6$ & $63.8 \pm 9.3$ & $64.8 \pm 9.2$ & N.S. \\
\hline Average $\mathrm{BMl}, \mathrm{kg} / \mathrm{m}^{2}$ & $21.9 \pm 4.2$ & $24.0 \pm 2.6$ & $24.6 \pm 3.8$ & N.S. \\
\hline JOA score & $49.8 \pm 9.7$ & $53.3 \pm 14.5$ & $48.6 \pm 11.0$ & N.S. \\
\hline UCLA activity score & $4.4 \pm 1.2$ & $5.0 \pm 0.9$ & $4.4 \pm 1.4$ & N.S. \\
\hline HHS & $56.9 \pm 9.9$ & $54.7 \pm 12.5$ & $49.2 \pm 10.6$ & N.S. \\
\hline Lumbar spine BMD, $\mathrm{g} / \mathrm{cm}^{2}$ & $0.8 \pm 0.2$ & $0.9 \pm 0.1$ & $0.9 \pm 0.1$ & N.S. \\
\hline
\end{tabular}

a significant difference between switch, ALD, and control groups; however, no significant difference between switch and ALD groups. Figure 8 shows that lumbar BMD AP side changes at 2 years were $+12.7 \pm 7.1 \%$ in the switch group, $+4.0 \pm 6.1 \%$ in the ALD group, and $2.8 \pm 5.8 \%$ in the control group, with significant differences between switch and ALD groups $(P=0.02)$ and switch and control $(P=0.00002)$. Figure 9 shows that the lumbar BMD lateral side changes at 2 years were + $15.4 \pm 11.7 \%$ in the switch group, $+6.7 \pm 8.4 \%$ in the ALD group, and $-6.1 \pm 11.2 \%$ in the control group. There was a significant difference between switch, ALD, and control groups, but no significant difference between switch and ALD groups. There were no significant differences in BMD changes among the three groups at zones $2,3,4,5$, and 6 .

\section{Discussion}

This RCT assessed the effects of three treatments on BMD around the implant and lumbar spine BMD for 2 years after THA. This study confirmed that switching from teriparatide to alendronate had significant effects in zones 1 and 7 and on lumbar BMD.

BMD loss around the femoral implant has been observed in several previous studies $[17,18]$. Although many factors are involved, environmental changes mainly caused by mechanical stress are likely most important. Differences in stem design, such as between the Zweymuller and fit-and-fill types, directly influence the mechanical property of the femur, thereby affecting the BMD as a result [4]. Particularly in the proximal medial region, i.e., zone 7 , the correlation between mechanical stress and BMD is significant [5]. By contrast, the shape

Table 2 Clinical function scores of the three patient groups 2 years after surgery

\begin{tabular}{lllll}
\hline & Switch group & ALD group & Control group & $P$ value \\
\hline JOA score & $92.7 \pm 7.1$ & $97.7 \pm 2.9$ & $94.8 \pm 5.7$ & N.S. \\
UCLA activity score & $6.5 \pm 0.7$ & $6.1 \pm 0.6$ & $6.4 \pm 1.0$ & N.S. \\
HHS & $96.8 \pm 4.1$ & $98.5 \pm 2.0$ & $96.7 \pm 4.1$ & N.S. \\
\hline
\end{tabular}

of the proximal femur, such as stove pipe or champagne flute, is also important for mechanical stress and BMD even when using the same implant type [19]. Thus, BMD loss around the implant likely involves an interrelationship between implant and femoral configuration. It is not realistic to change such mechanical configuration after surgery, making drug intervention to prevent BMD less practical.

Several studies have tested the ability of bisphosphonate to prevent BMD loss around the femoral implant $[10,11,20-24]$, whereas there is no clear evidence of poorer clinical outcomes due to BMD loss after THA. Although the direct participation of BMD is not clear, bisphosphonate was associated with a lower risk of aseptic revision in patients undergoing primary THA for osteoarthritis $[6,25]$. Thus, the prevention of BMD loss by some anti-osteoporosis agents may be desirable in clinical setting. In fact, alendronate, a first-line drug for osteoporosis, was recognized as effective for the prevention of BMD loss around the implant $[10,11]$. However, long-term continuous bisphosphonate treatment has been associated with atypical periprosthetic fractures

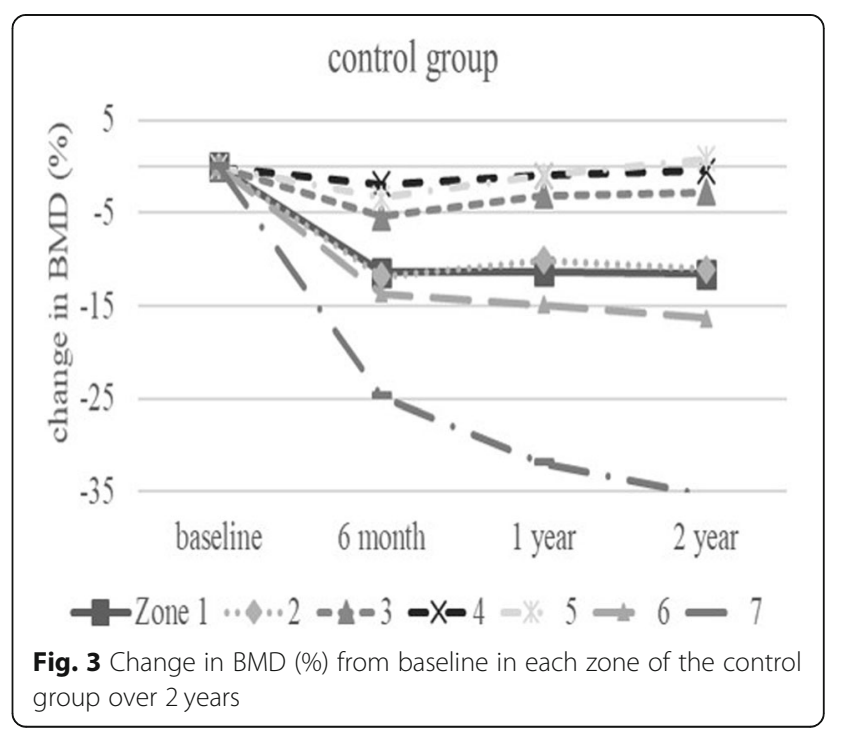




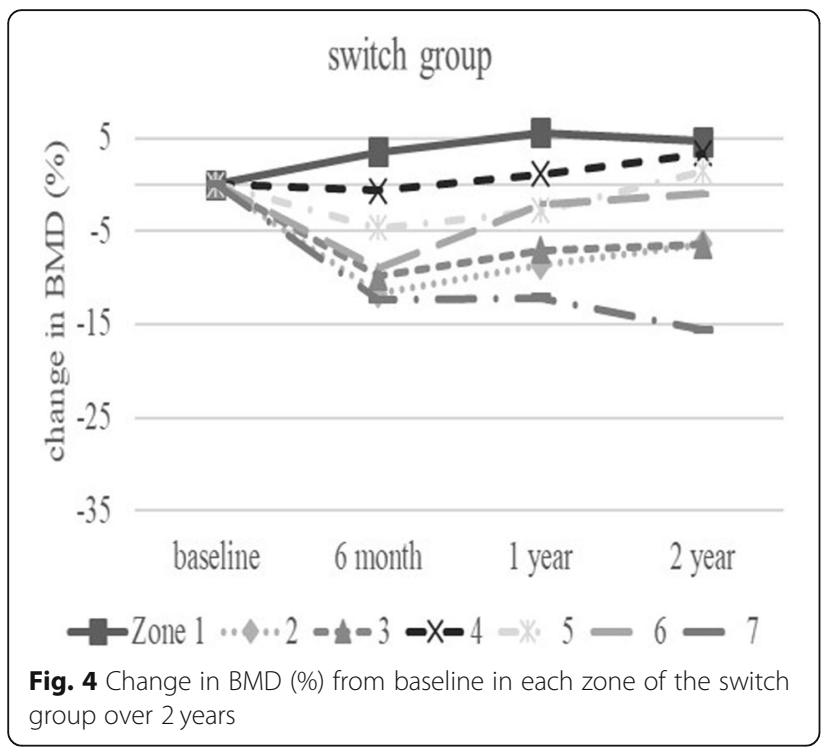

$[26,27]$. Periprosthetic fracture rates following primary THA were reported to be $1.1 \%$ in a large US cohort [28] and $0.64 \%$ at 10 years in the Swedish hip registry [29]. Moreover, bisphosphonate use was associated with a higher risk of periprosthetic fractures in younger patients with normal bone quantity [6]. Thus, an alternative drug may be desirable for the prevention of BMD loss after THA. A RCT showed that teriparatide and alendronate had equivalent effects [12]. However, patients on teriparatide require switching to another agent [30].

Although many previous studies showed that teriparatide was effective for osteoporosis treatment [31-36], the combination of parathyroid hormone $(\mathrm{PTH})$ and alendronate was inferior to $\mathrm{PTH}$ alone in preventing loss of lumbar BMD [13]. In addition, a randomized trial found that switching from teriparatide to alendronate

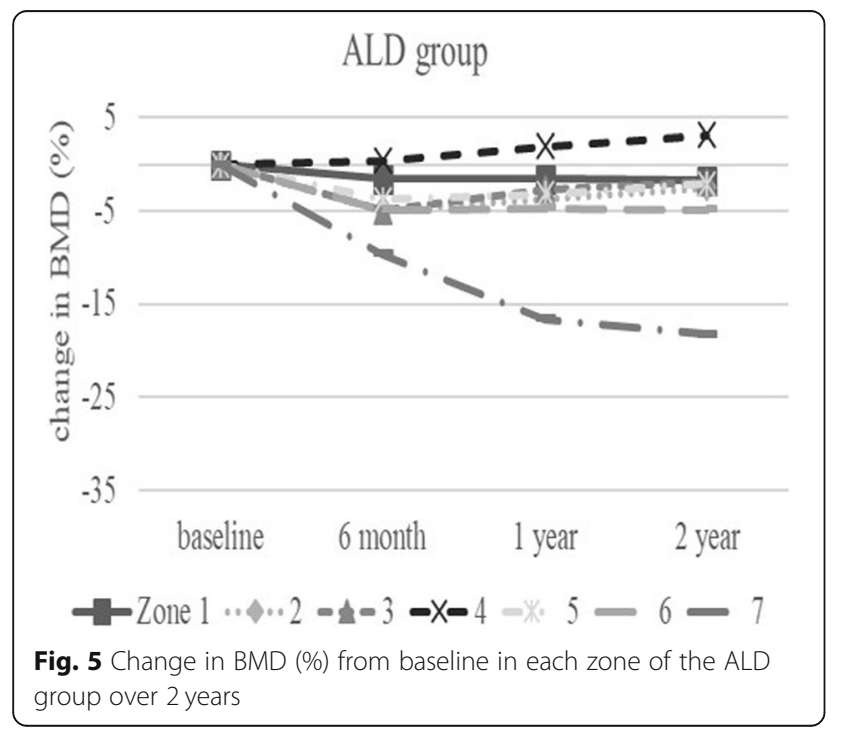

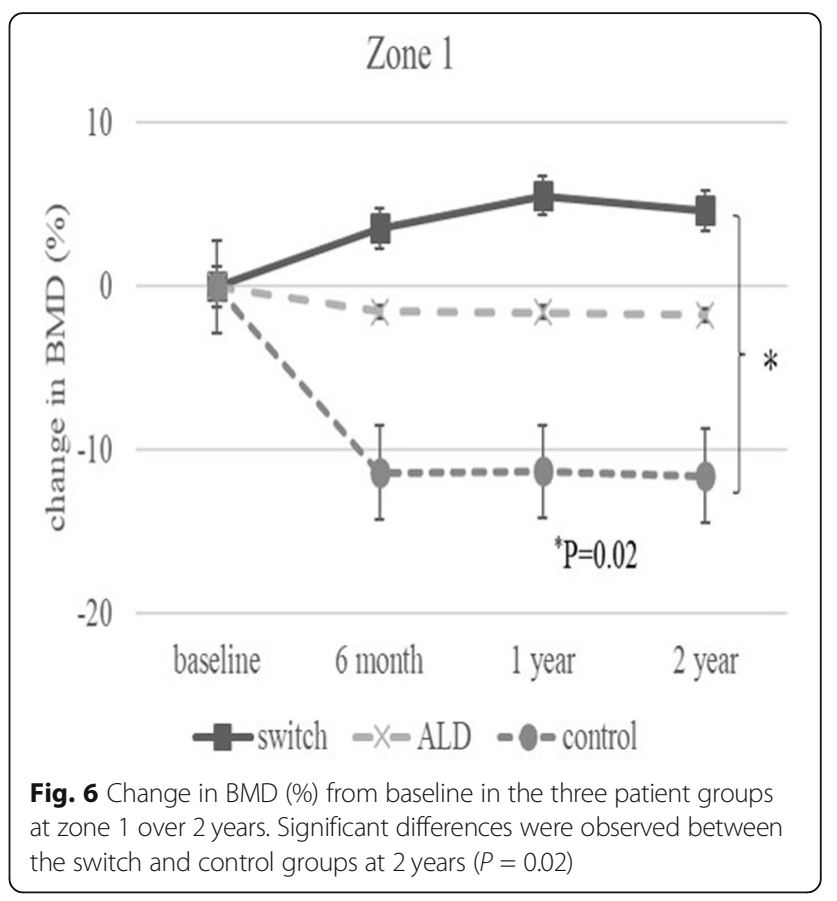

was superior to alendronate alone in maintaining spinal BMD [13]. Furthermore, teriparatide followed by alendronate resulted in greater gains in areal BMD than did alendronate alone at sites of rich cancellous bone [14]. Although the proportions of the cortical and cancellous bone at the femur have not been clearly determined and may depend on the individual, zone 1 , in the greater trochanteric region, generally contains plenty of the

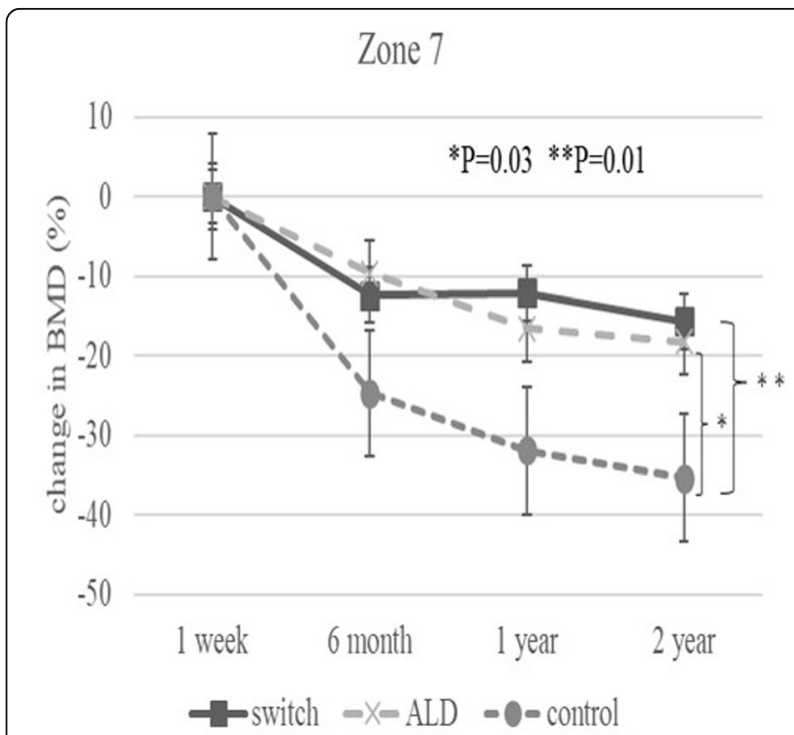

Fig. 7 Change in BMD (\%) from baseline in the three patient groups at zone 7 over 2 years. Significant differences were observed between the switch and control groups $(P=0.01)$ and between ALD and control groups at 2 years $(P=0.03)$ 


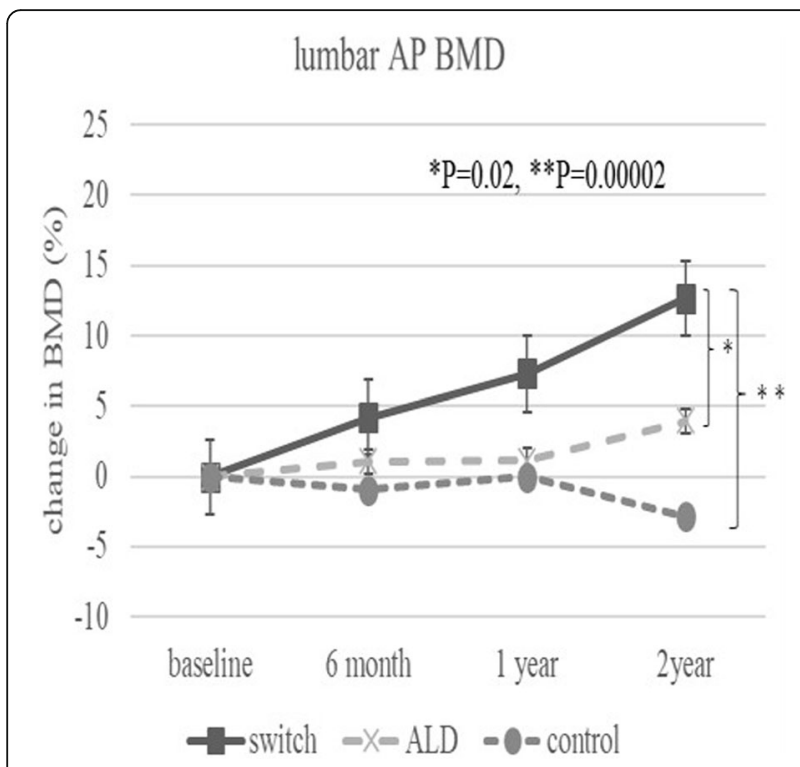

Fig. 8 Change in BMD (\%) from baseline in the three patient groups at the lumbar spine BMD AP side over 2 years. Significant differences were observed between the switch and ALD groups $(P=0.02)$ and between the switch and control groups $(P=0.00002)$

cancellous bone. This may explain, at least, in part the results of the present study that there was no difference in ALD groups in zone 1. In this study, BMD loss in both zones 1 and 7 and the lumbar spine was significantly prevented in the switch group; therefore, switching teriparatide to alendronate was effective for periprothetic and lumbar spine. A major limitation was that the bone strength was not evaluated in this study.

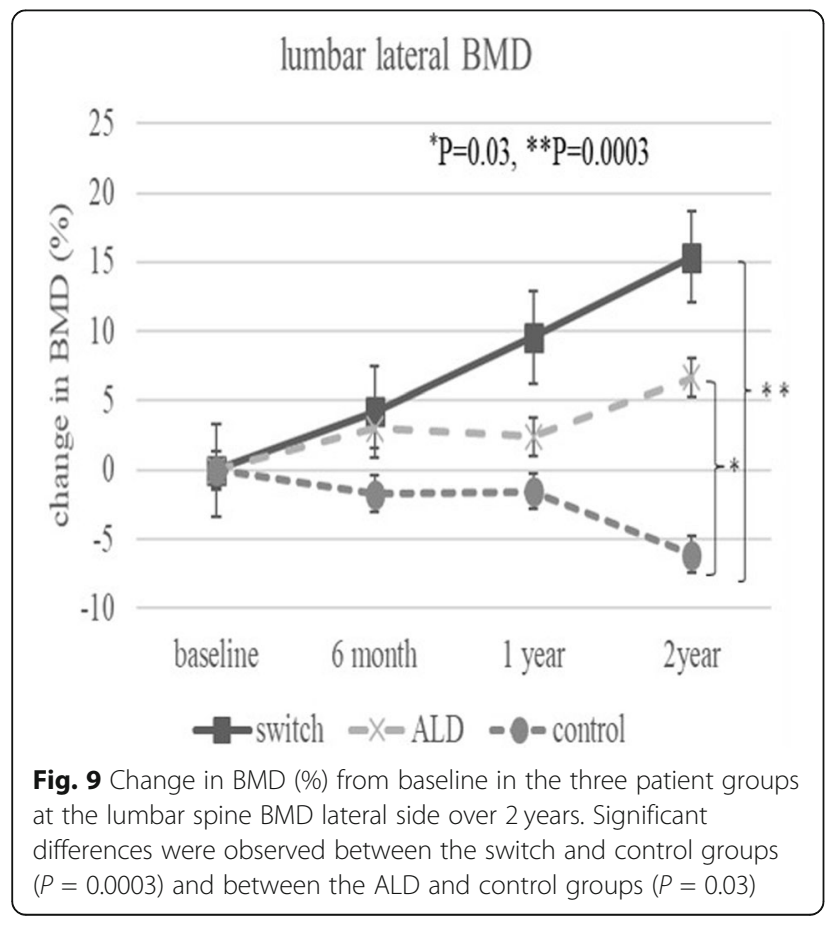

Biomechanical bone strength is not only dependent on BMD. Teriparatide has been reported to reduce peripheral or cortical volumetric BMD [33, 34, 37], although another study found that the femoral strength ratio was significantly higher in patients treated with teriparatide than with alendronate [38]. These results were consistent with findings showing that the correlation coefficient between change in femoral strength and change in trabecular volumetric BMD was higher in patients treated with teriparatide than with alendronate. In addition, teriparatide was reported to increase osseointegration and the mechanical strength of the bone-implant interface [39]. Thus, teriparatide may have several potential advantages regarding bone strength and/or increased osseointegration.

In conclusion, this randomized controlled trial assessed the effect of switching from teriparatide to alendronate in preventing BMD loss around the implant after THA. Switching therapy had a significant effect at the lumbar spine and the proximal femur around implants, including zones 1 and 7. BMD at zone 1 was significantly higher in the switch than in the control group, but no significant difference between ALD and control group. Switching from teriparatide to alendronate may be as useful as alendronate alone for preventing periprosthetic BMD after THA.

\section{Conclusions}

Switching teriparatide to alendronate is more effective than alendronate alone in maintaining zone1 BMD and increasing lumber spine BMD.

\section{Abbreviations}

ALD: Alendronate; AP: Anterior-posterior; BMD: Bone mineral density; DEXA: Dual-energy X-ray absorptiometry; HHS: Harris Hip Score;

JOA: Japanese Orthopaedic Association; PTH: Parathyroid hormone; RCT: Randomized controlled trial; ROIs: Regions of interest; THA: Total hip arthroplasty; UCLA: University of California, Los Angeles; UMIN: University Hospital Medical Information Network

\section{Acknowledgements}

I would like to express my sincere appreciation to those who supported the research and cooperated in the preparation of the manuscript.

\section{Authors' contributions}

NK is Corresponding author. $\mathrm{HC}, \mathrm{HI}, \mathrm{TT}, \mathrm{SH}$, and $\mathrm{Yl}$ analyzed and interpreted the patient data. All authors read and approved the final manuscript.

Funding

There is no funding source.

\section{Availability of data and materials}

All data generated or analyzed during this study are included in this published article [and its supplementary information files].

\section{Ethics approval and consent to participate}

This randomized controlled trial was an extension of a previous reported study registered in the University Hospital Medical Information Network (UMIN) clinical trial registry (registry number: UMIN000016158).

\section{Consent for publication} Not applicable 


\section{Competing interests}

The authors declare that they have no competing interests.

\section{Author details}

'Department of Orthopaedic Surgery, Yokohama City University, 3-9 Fukuura, Kanazawa-ku, Yokohama 236-0004, Japan. ${ }^{2}$ Department of Orthopaedic Surgery, Yokohama City University Medical Center, 4-57 Urafune-cho, Minami-ku, Yokohama 232-0024, Japan.

Received: 5 December 2019 Accepted: 6 January 2020

Published online: 16 January 2020

\section{References}

1. Al Muderis M, Bohling U, Grittner U, Gerdesmeyer L, Scholz J. Cementless total hip arthroplasty using the Spongiosa-l fully coated cancellous metal surface: a minimum twenty-year follow-up. The Journal of bone and joint surgery American volume. 2011;93(11):1039-44.

2. McLaughlin JR, Lee KR. Uncemented total hip arthroplasty with a tapered femoral component: a 22- to 26-year follow-up study. Orthopedics. 2010;33(9):639.

3. Kröger $H$, Venesmaa P, Jurvelin J, Miettinen $H$, Suomalainen O, Alhava E. Bone density at the proximal femur after total hip arthroplasty. Clin Orthop Relat Res. 1998;352:66-74.

4. Hirata $Y$, Inaba $Y$, Kobayashi N, Ike H, Fujimaki H, Saito T. Comparison of mechanical stress and change in bone mineral density between two types of femoral implant using finite element analysis. J Arthroplasty. 2013;28(10):1731-5.

5. Ike H, Inaba Y, Kobayashi N, Hirata Y, Yukizawa Y, Aoki C, et al. Comparison between mechanical stress and bone mineral density in the femur after total hip arthroplasty by using subject-specific finite element analyses. Comput Methods Biomech Biomed Engin. 2015;18(10):1056-65.

6. Khatod M, Inacio MCS, Dell RM, Bini SA, Paxton EW, Namba RS. Association of bisphosphonate use and risk of revision after THA: outcomes from a US total joint replacement registry. Clin Orthop Relat Res. 2015;473(11):3412-20.

7. Leonardsson O, Kärrholm J, Åkesson K, Garellick G, Rogmark C. Higher risk of reoperation for bipolar and uncemented hemiarthroplasty. Acta Orthopaedica. 2012;83(5):459-66.

8. Sköldenberg OG, Sjöö H, Kelly-Pettersson P, Bodén H, Eisler T, Stark A, et al. Good stability but high periprosthetic bone mineral loss and late-occurring periprosthetic fractures with use of uncemented tapered femoral stems in patients with a femoral neck fracture. Acta Orthopaedica. 2014;85(4):396-402.

9. Knusten AR, Ebramzadeh E, Longjohn DB, Sangiorgio SN. Systematic analysis of bisphosphonate intervention on periprosthetic BMD as a function of stem design. J arthroplasty. 2014;29(6):1292-7.

10. Iwamoto N, Inaba Y, Kobayashi N, Ishida T, Yukizawa Y, Saito T. A comparison of the effects of alendronate and alfacalcidol on bone mineral density around the femoral implant and in the lumbar spine after total hip arthroplasty. J Bone Joint Surg Am. 2011;93(13):1203-9.

11. Arabmotlagh M, Pilz M, Warzecha J, Rauschmann M. Changes of femoral periprosthetic bone mineral density 6 years after treatment with alendronate following total hip arthroplasty. J Orthop Res. 2009;27(2):183-8.

12. Kobayashi N, Inaba Y, Uchiyama M, Ike H, Kubota S, Saito T. Teriparatide versus alendronate for the preservation of bone mineral density after total hip arthroplasty - a randomized controlled trial. J Arthroplasty. 2016;31(1):333-8.

13. Black DM, Greenspan SL, Ensrud KE, Palermo L, McGowan JA, Lang TF, et al. The effects of parathyroid hormone and alendronate alone or in combination in postmenopausal osteoporosis. N Engl J Med. 2003;349(13):1207-15.

14. Black DM, Bilezikian JP, Ensrud KE, Greenspan SL, Palermo L, Hue T, et al. One year of alendronate after one year of parathyroid hormone (1-84) for osteoporosis. N Engl J Med. 2005;353(6):555-65.

15. Kaufman J-M, Orwoll E, Goemaere S, San Martin J, Hossain A, Dalsky GP, et al. Teriparatide effects on vertebral fractures and bone mineral density in men with osteoporosis: treatment and discontinuation of therapy. Osteoporos Int. 2005;16(5):510-6.

16. Kanda Y. Investigation of the freely available easy-to-use software "EZR" for medical statistics. Bone Marrow Transplant. 2013;48(3):452-8.

17. Nishii T, Sugano N, Masuhara K, Shibuya T, Ochi T, Tamura S. Longitudinal evaluation of time related bone remodeling after cementless total hip arthroplasty. Clin Orthop Relat Res. 1997;339(339):121-31.

18. Venesmaa PK, Kröger HPJ, Miettinen HJA, Jurvelin JS, Suomalainen OT, Alhava EM. Monitoring of periprosthetic BMD after uncemented total hip arthroplasty with dual-energy X-ray absorptiometry-a 3-year follow-up study. J Bone Miner Res. 2001;16(6):1056-61.
19. Oba M, Inaba Y, Kobayashi N, Ike H, Tezuka T, Saito T. Effect of femoral canal shape on mechanical stress distribution and adaptive bone remodelling around a cementless tapered-wedge stem. Bone joint res. 2016;5(9):362-9.

20. Arabmotlagh M, Rittmeister M, Hennigs T. Alendronate prevents femoral periprosthetic bone loss following total hip arthroplasty: prospective randomized double-blind study. J Orthop Res. 2006;24(7):1336-41.

21. Fokter SK, Komadina R, Repše-Fokter A. Effect of etidronate in preventing periprosthetic bone loss following cemented hip arthroplasty: a randomized, double blind, controlled trial. Wiener klinische Wochenschrift. 2006;118(S2):23-8.

22. Kinov $P$, Tivchev $P$, Doukova $P$, Leithner A. Effect of risedronate on bone metabolism after total hip arthroplasty: a prospective randomised study. Acta orthopaedica Belgica. 2006;72(1):44-50

23. Yamaguchi K, Masuhara K, Yamasaki S, Nakai T, Fuji T. Cyclic therapy with etidronate has a therapeutic effect against local osteoporosis after cementless total hip arthroplasty. Bone. 2003;33(1):144-9.

24. Yamasaki S, Masuhara K, Yamaguchi K, Nakai T, Fuji T, Seino Y. Risedronate reduces postoperative bone resorption after cementless total hip arthroplasty. Osteoporos Int. 2007;18(7):1009-15.

25. Teng S, Yi C, Krettek C, Jagodzinski M. Bisphosphonate use and risk of implant revision after total hip/knee arthroplasty: a meta-analysis of observational studies. Dong Y, editor. PLOS ONE. 2015;10(10):e0139927.

26. Erviti J, Alonso Á, Oliva B, Gorricho J, López A, Timoner J, et al. Oral bisphosphonates are associated with increased risk of subtrochanteric and diaphyseal fractures in elderly women: a nested case-control study. BMJ Open. 2013;3(1):e002091

27. Goh S-K, Yang KY, Koh JSB, Wong MK, Chua SY, Chua DTC, et al. Subtrochanteric insufficiency fractures in patients on alendronate therapy. J Bone Joint Surg Br. 2007;89-B(3):349-53.

28. Berry DJ. Epidemiology. Orthopedic Clinics of North America. 1999;30(2):183-90.

29. Lindahl $H$. Epidemiology of periprosthetic femur fracture around a total hip arthroplasty. Injury. 2007;38(6):651-4.

30. Leder BZ, Neer RM, Wyland JJ, Lee HW, Burnett-Bowie S-AM, Finkelstein JS Effects of teriparatide treatment and discontinuation in postmenopausal women and eugonadal men with osteoporosis. J Clin Endocrinol Metab. 2009;94(8):2915-21.

31. Uusi-Rasi K, Semanick LM, Zanchetta JR, Bogado CE, Eriksen EF, Sato M, et al. Effects of teriparatide [rhPTH (1-34)] treatment on structural geometry of the proximal femur in elderly osteoporotic women. Bone. 2005;36(6):948-58.

32. Zanchetta JR, Bogado CE, Ferretti JL, Wang O, Wilson MG, Sato M, et al. Effects of teriparatide [recombinant human parathyroid hormone (1-34)] on cortical bone in postmenopausal women with osteoporosis. J Bone Miner Res. 2003:18(3):539-43.

33. Macdonald HM, Nishiyama KK, Hanley DA, Boyd SK. Changes in trabecular and cortical bone microarchitecture at peripheral sites associated with 18 months of teriparatide therapy in postmenopausal women with osteoporosis. Osteoporos Int. 2011;22(1):357-62.

34. Borggrefe J, Graeff C, Nickelsen TN, Marin F, Glüer CC. Quantitative computed tomographic assessment of the effects of 24 months of teriparatide treatment on 3D femoral neck bone distribution, geometry, and bone strength: results from the EUROFORS study. J Bone Miner Res. 2010;25(3):472-81.

35. Keaveny TM, Donley DW, Hoffmann PF, Mitlak BH, Glass EV, San Martin JA. Effects of teriparatide and alendronate on vertebral strength as assessed by finite element modeling of QCT scans in women with osteoporosis. J Bone Miner Res. 2007;22(1):149-57.

36. Fokter SK, Komadina R, Repše-Fokter A. Effect of etidronate in preventing periprosthetic bone loss following cemented hip arthroplasty: a randomized, double blind, controlled trial. Wiener klinische Wochenschrift. 2006;118(S2):23-8

37. McClung MR, San Martin J, Miller PD, Civitelli R, Bandeira F, Omizo M, et al. Opposite bone remodeling effects of teriparatide and alendronate in increasing bone mass. Arch intern med. 2005;165(15):1762-8.

38. Keaveny TM, McClung MR, Wan X, Kopperdahl DL, Mitlak BH, Krohn K. Femoral strength in osteoporotic women treated with teriparatide or alendronate. Bone. 2012;50(1):165-70.

39. X. Yang, A. Dvorzhinskiy, V.L. Craveiro, C. Brial, B. Ricciardi, F.P. Ross. 2015 Annual Meeting of the American Society for Bone and Mineral Research Seattle, WA October 9-12, 2015. J Bone Miner Res 2015;30(S1):S1-S1.

\section{Publisher's Note}

Springer Nature remains neutral with regard to jurisdictional claims in published maps and institutional affiliations. 